\title{
Predictors of frequency of condom use and attitudes among sexually active female military personnel in Nigeria
}

This article was published in the following Dove Press journal:

HIVIAIDS - Research and Palliative Care

16 April 2010

Number of times this article has been viewed

\author{
E James Essien' \\ Osaro Mgbere ${ }^{2}$ \\ Emmanuel Monjok' \\ Ernest Ekong ${ }^{3}$ \\ Susan Abughosh' \\ Marcia M Holstad ${ }^{4}$ \\ 'Institute of Community Health, \\ University of Houston, Texas \\ Medical Center, Houston, TX, USA; \\ ${ }^{2}$ Houston Department of Health and \\ Human Services, Houston, TX, USA; \\ ${ }^{3}$ Institute for Health Research and \\ Development, Yaba, Lagos, Nigeria; \\ ${ }^{4}$ Nell Hodgson School of Nursing, \\ Emory University, Atlanta, GA, USA
}

Correspondence: E James Essien Institute of Community Health, University of Houston, Texas Medical Center, I44I Moursund Street, Houston, TX 77030, USA

$\mathrm{Tel}+\mathrm{I} 7137958393$

Fax +I 7|37958383

Email ejessien@uh.edu
Background: Despite awareness of condom efficacy, in protecting against both human immunodeficiency virus/sexually transmitted diseases (HIV/STDs) and unintended pregnancy; some females find it difficult to use or permit condom use consistently because of the power imbalances or other dynamics operating in their relationships with males. The purpose of this study was to determine the factors that predict the frequency of condom use and attitudes among sexually active female military personnel in Nigeria.

Methods: This study used a cross-sectional design in which a total of 346 responses were obtained from consenting female military personnel in two cantonments in Southwestern Nigeria between 2006 and 2008. The study instrument was designed to assess HIV/acquired immunodeficiency syndrome (AIDS) knowledge (HAK), HIV risk behaviors (HRB), alcohol and drug use, condom attitudes and barriers (CAS) condom use self-efficacy (CUS) and social support to condom use (SSC). The sociodemographic characteristics of participants were also captured. Univariate analysis and multivariable logistic regression were used for modeling the predictors of condom use.

Results: The results showed that $63 \%$ of the respondents reported using condoms always, $26 \%$ sometimes used condoms and $11 \%$ never used condoms during a sexual encounter in the past three months. Univariate analysis revealed that significant associations existed between CAB $(P<0.05), \operatorname{HRB}(P<0.01)$ and SSC $(P<0.01)$ with the frequency of condom use. The following sociodemographic variables: age, marital status, number of children, employment status and type of sexual relationship were also significantly $(P \leq 0.05)$ associated with consistent condom use in the study group. Multivariate analysis indicated that marital status, type of relationship and $\mathrm{CAB}$ were the only significant predictors $\left(r^{2}=0.37 ; P \leq 0.05\right)$ of condom use behaviors after adjusting for all other factors in the model.

Conclusions: Findings indicate that consistent condom use could be enhanced through gender-specific intervention programs that incorporate the predictor variables identified. These are likely to be successful in decreasing sexual risk behaviors in the subpopulation.

Keywords: HIV/AIDS, condom use, risky behavior, military personnel, Nigeria

\section{Introduction}

The HIV/AIDS epidemic is a growing public health problem in Nigeria. The epidemic has extended beyond the commonly classified high-risk groups and is now common in the general population. The Joint United Nations Program on HIV/AIDS (UNAIDS) estimates that around $3.1 \%$ of adults, between ages 15-49 are living with HIV and AIDS in Nigeria. ${ }^{1}$ Although the HIV prevalence is much lower in Nigeria than in other African countries such as South Africa and Zambia, the size of Nigeria's 
population (around 148 million) meant that by the end of 2007, there were an estimated 2.6 million people infected with HIV. ${ }^{1}$ The gender differences in the epidemic remain glaring, with women being infected more often than men. In 2006 UNAIDS estimated that women accounted for $61.5 \%$ of all adults aged 15 years and above living with $\mathrm{HIV}^{2}$ Heterosexual transmission is the main portal of entry of HIV in Nigeria. While awareness on HIV is relatively high especially among urban populations, it appears that the high level of knowledge of HIV has little impact on the myths and misconceptions about HIV transmission. ${ }^{3}$ Risky sexual practices have been reported in several subpopulations such as in young persons, ${ }^{4}$ commercial sex workers, ${ }^{5}$ commercial drivers, ${ }^{6}$ and Nigerian military, ${ }^{7-9}$ thus indicating the need for improved intervention programs in these populations.

Military populations, in general, have increased vulnerability to HIV infection, compared to the general civilian populations. Several factors place men and women in military services at increased risk of HIV infection. Nigerian military personnel, like most militaries are in the most sexually active age group (15 to 35 years) and thus are at greatest risk of contracting HIV. Since they are regularly away from home for long periods, away from their regular sexual partners, many of them engage in risky behaviors as a means of relieving the tension of loneliness and stress. ${ }^{10}$ In addition, the occupation gives them a sense of invulnerability and exposes them to alcohol and drug consumption and commercial sex workers. Risk factors among the military also include high rates of sexual partner change, elevated rates of STDs, low rates of condom use with commercial sex workers and other casual partners, and significant mixing between groups having high and low risk behavior patterns. ${ }^{11}$ In an intervention study to evaluate the effectiveness of a situationally-based HIV riskreduction for the Nigerian uniformed services, ${ }^{12}$ it was noted that at baseline, $36 \%$ of the participants reported that they had not thought of using condoms with their casual partners.

Therefore, a reduction in HIV incidence in Nigeria would require not only a fall in the level of higher-risk sex but also a rise in condom use during higher-risk sex; and condom use during sexual intercourse is the most effective strategy for the prevention of heterosexual transmission of STDs and HIV infection. Condoms, when used correctly and consistently, can reduce the rate of HIV transmission by $80 \%$ to $90 \% 13,14$ and pregnancy by $91 \%$ to $99 \% .^{15}$

In Nigeria, females constitute $6 \%$ to $10 \%$ of the military ${ }^{16}$ and are exposed to the same, sometimes even greater, pressure as men to enter into casual sexual relationships. Despite awareness of condom efficacy, most females generally find it difficult to use condoms consistently because of the power imbalances or other dynamics operating in their relationships with males. Studies comparing condom use among women who had access to both male and female condoms and those with access to male condoms alone have shown that female condom availability does increase protection. ${ }^{17-19}$

Negative attitudes toward using male condoms tend to be associated with higher rates of sexual risk. Little has been written about the factors that influence women's attitudes toward condom use, and this has implications for HIV intervention efforts. Understanding factors associated with safer sexual practices and condom use among female military personnel is considered a vital component of HIV/STD prevention strategies. In this article, we determine the predictors of the frequency of condom use and condom-related attitudes among sexually active female military personnel in Nigeria. Such information can help improve the design of intervention campaigns to reduce the spread of HIV in this group, among high-risk groups and the general population.

\section{Methods}

\section{Participants and procedures}

Using a cross-sectional design, 346 female military personnel were recruited from two military cantonments in the Southwestern part of Nigeria to participate in the study. The number represented $90 \%$ of the initial sample population of 386 screened. The two cantonments were chosen because they served as camps for recruitment, training and entry points for returning military personnel deployed on peacekeeping operations and foreign missions; and therefore, offered an ideal environment for our study. The participants formed the baseline population of an intervention study. ${ }^{20}$ In order to consider the participants at risk of potential HIV infection, this study required them to be sexually active and to meet certain criteria, which include: aged 18 years or older, selfreported unprotected vaginal intercourse with two or more different partners in the past six months, or having been diagnosed and treated for a sexually transmitted disease in the last year, residence at the study sites, ability to communicate in English language, and willingness to sign a consent form for study participation. The study was conducted between 2006 and 2008 and received Institutional Review Board (IRB) approval from both the University of Houston in the United States and Institute for Health Research and Development in Nigeria. More details of the settings and procedures are available elsewhere. ${ }^{20}$ 


\section{Measures}

The study used an adapted version of a previously validated instrument ${ }^{21}$ with minor modifications made to fit the cultural settings in Nigeria. The instrument which was cross-validated with the present study population comprised of composite items used to capture socio-demographic information, and to measure HIV/AIDS-related knowledge (HAK), condom use and attitudes, HIV risk avoidance intentions, risk reduction strategies, alcohol consumption and substance use behaviors. Condom use, as defined in our study refers to using either the female condom or allowing use of the male condom by a partner during sexual encounter. The main outcome variable was frequency of condom use during the past three months. The variables of interest used in the present analysis are described in detail below.

\section{Sociodemographics}

Standard questions were used to assess participants' age, marital status, race/ethnicity, employment status, annual income, level of education, religion, sexual relationships, number of children, incarceration history, and personally knowing someone with HIV/AIDS.

\section{HIVIAIDS related knowledge}

A 10-item test was used to assess HIV/AIDS risk prevention knowledge. The items elicited information on HIV transmission knowledge, condom use knowledge, and AIDSrelated knowledge. A categorical scale with three levels of responses (yes, no, don't know) was used. Example items included "Can a woman give the AIDS virus to a man?" (yes), "Can you get AIDS by touching a person with AIDS?" (no). Each correct answer was scored 1 point, and a total score of 10 points was attainable based on the number of questions. Participants that scored 5 points or less were classified as having 'low' knowledge and those that score above 5 points were classified as having 'high' knowledge. The internal consistency of the HIV/AIDS knowledge scale in our sample was (Cronbach's $\alpha=0.74$ ).

\section{Frequency of condom use}

Participants were asked when they have sex, how often they used a condom in the past 3 months prior to the study. Responses were categorized into never, sometimes or always. We based our classification and definition of condom usage after the work of Davis and Weller. ${ }^{15}$ The never-used category indicated that condoms were not used during any acts of vaginal intercourse $(0 \%)$. The sometimes-used category included intermediate estimates of use (1\%-99\%) and combinations of never-used, sometimes-used ( $0 \%-99 \%)$ or always-used $(100 \%)$. The always-used category indicated that a condom was used for $100 \%$ of penetrative acts of vaginal intercourse.

\section{Condom attitudes and barriers}

Attitudes toward male and female condoms were assessed using items that measured intent and utilization of condoms. Condom attitudes were assessed using a four-item test. The participants responded on a four-point Likert scale ranging from 1 (strongly disagree) to 4 (strongly agree). The sample items included: "Using female condoms interrupt the pleasure of sex", "Male condoms reduce the fun of sex", "I would be embarrassed to buy condoms", and "Male condoms are a hassle to use". Negative attitudinal items were reversed scored and all items were summed for an overall measure, in which lowest scores represented more positive attitudes toward condoms (range $=17-74$ ). The scale was found to have satisfactory internal consistency (Cronbach's $\alpha=0.58$ ).

\section{Condom use self-efficacy}

Condom use self-efficacy (CUS) was assessed using a sixitem scale that examined the participants' self- efficacy for condom use, HIV testing and substance use prior to sexual intercourse. Examples of statements in the past three months prior to study: "Talked with sex partner about using male condoms for safer sex", "Did not have sex because you did not have a condom". The questions were anchored on the best estimate of number of times an event occurred within the past three-months. The total number of times the different event scenarios occurred represented the selfefficacy level, with the highest value indicating a more favorable self-efficacy and lowest value the less favorable self-efficacy. The internal consistency of the CUS scale in our sample was (Cronbach's $\alpha=0.78$ ).

\section{Social support to condom use}

Twelve-item scale was used to measure participants' perceived social support for condom use. Sample statements of the item scale included: "My partner(s) prefer(s) that we use a male condom during sex", "My friends always use male condoms during sex", "Most of my friends think that female condoms are just too much of a hassle to use", "My friends believe that insisting on using male condoms means that you don't trust your partner". These statements were endorsed with a four-point Likert-type response scale ranging from 1 (strongly disagree) to 4 (strongly agree). Negative attitudinal items were reversed scored, and all items were summed to determine 
the overall measure. The possible range for social support measure was $12-48$, with 48 indicating the highest perceived social support. The reliability for this scale was moderate (Cronbach's $\alpha=0.52$ ).

\section{HIV risk behaviors}

Sexual- and drug-related risk behaviors among participants were assessed in the past three months using 10 items. Ten questions eliciting risky behaviors such as the following were asked: "Have you ever drank alcohol heavily before having sex", "Have you ever had sex with a man who you believe had sex with another man?", "Have you given someone money, drugs or other things to get sex?", "Have you had a sexual disease such as syphilis, gonorrhea, herpes or chlamydia?" "Have you ever been tested for HIV?" Answers to the questions were based on a 'yes' or 'no' response. All responses were coded as 1 for 'yes' and 2 for 'no', and later summed, with possible score range of 10-22. Higher scores indicate extreme involvement in risk behaviors. The HRB scale internal consistency was considered adequate (Cronbach's $\alpha=0.66$ ).

\section{Data analysis}

Data analyses were based on 346 participants who reported being sexually active in the previous 12 months. The frequency of condom use was used as an outcome variable in the analysis. We examined the bivariate associations between individual socio-demographic variables and frequency of condom use using Pearson's $\chi^{2}$ statistic. Analysis of variance (ANOVA) was used to assess the differences in means of continuous variables: HAK, CAB, HRB, CUS, and SSC based on frequency of condom use. Furthermore, condom use behavior was re-grouped into two categories as follows: consistent users (participants that used condoms always during sexual intercourse in the past three months prior to the study) and nonconsistent users (participants that either sometimes or never used condom during sexual intercourse in the past three months prior to the study. Appropriate dichotomous categories of predictor variables were created for HAK, CAB, HRB, CUS, and SSC. Univariate analysis was conducted to examine the magnitude and significance of the bivariate associations between independent dichotomous variables and the outcome variable. The corresponding probability level, unadjusted prevalence odds ratio (UPOR), and $95 \%$ confidence intervals (CI) were computed for each bivariate association.

Based on the outcome of this analysis, the predictor variables for use in multivariable logistic regressions were selected a priori, if they were significant at the 0.10 level in the bivariate analysis or if they were considered important. Age, education level, and marital status were identified $a$ priori as important variables and were selected for inclusion in the final multivariate models, regardless of whether they met the specified criteria. Factors identified as significantly associated with the condom use behavior in the bivariate analysis were entered into a multivariable logistic regression analysis to assess the independent contribution of each factor in predicting condom usage, and to simultaneously adjust for potential confounders. Finally, we conducted a model Likelihood ratio test to determine the goodness of fit of the model. Adjusted prevalence odds ratio (APOR) with 95\% CI was computed for each association. All statistics were two-tailed at 0.05 significance level, and were performed using SPSS software (version 16.0; SPSS Inc., Chicago, USA).

\section{Results}

\section{Factors associated with condom use}

Of the total population of 386 sampled, complete responses were obtained from 346 female military personnel, with a response rate of $90 \%$. A detailed description of the sociodemographic characteristics of the study population comprising of 346 participants has been given elsewhere by Essien et al. ${ }^{22}$ Table 1 presents the association between the socio-demographic characteristics and frequency of condom use in the study population. Overall, majority of the participants, $63 \%$, reported using condoms always, while $26 \%$ indicated that they used condoms sometimes and $11 \%$ of them reported that they never used condoms during sexual encounters in the past three months prior to the study. There were significant associations $(P \leq 0.05)$ across all variables considered, except for religion, annual income and personally knowing someone with HIV (Table 1). About $43.5 \%$ of the respondents in the age category greater than or equal to 30 years used condoms always compared to $9 \%$ that never used condoms. Also, a significantly $(P<0.001)$ higher proportion of singles than married ones, tend to use condoms always (54.8\% vs $8.8 \%$ ). Of those who used condoms always, a ratio of 1:1 was reported for singles and multiple partners, respectively. There was a tendency for female participants with casual partners to use condoms always compared to noncasual ones (36.4\% vs. $27.0 \%$ ), although majority of the later group used condoms sometimes (19.4\%).

Based on the scores, the study participants generally had high level of HAK, with no significant difference noted between the frequency of condom use and HAK 
Table I Sociodemographic characteristics of study participants by frequency of condom use

\begin{tabular}{|c|c|c|c|c|c|c|c|c|}
\hline \multirow[t]{3}{*}{ Variables } & \multicolumn{6}{|c|}{ Frequency of condom use } & \multicolumn{2}{|c|}{ Test statistics $^{\mathrm{a}}$} \\
\hline & \multicolumn{2}{|c|}{ Always $(n=218)$} & \multicolumn{2}{|c|}{ Sometimes $(n=88)$} & \multicolumn{2}{|c|}{ Never $(n=39)$} & \multirow[t]{2}{*}{$\chi^{2}$} & \multirow[t]{2}{*}{$P$-value } \\
\hline & $\mathbf{n}$ & $\%$ & $\mathbf{n}$ & $\%$ & $\mathbf{n}$ & $\%$ & & \\
\hline \multicolumn{9}{|l|}{ Age (years) } \\
\hline$<30$ years & 68 & 19.7 & 11 & 3.2 & 8 & 2.3 & & \\
\hline$\geq 30$ years & 150 & 43.5 & 77 & 22.3 & 31 & 9.0 & 12.1 & $0.002 * *$ \\
\hline \multicolumn{9}{|l|}{ Education level } \\
\hline Less than high school & 24 & 7.0 & 8 & 2.3 & 13 & 3.8 & & \\
\hline High school and above & 194 & 56.4 & 79 & 23.0 & 26 & 7.6 & 16.1 & $0.000 * * *$ \\
\hline \multicolumn{9}{|l|}{ Marital status ${ }^{b}$} \\
\hline Single & 187 & 54.8 & 32 & 9.4 & 15 & 4.4 & & \\
\hline Married & 30 & 8.8 & 55 & 16.1 & 22 & 6.5 & 85.6 & $0.000 * * *$ \\
\hline \multicolumn{9}{|l|}{ Number of children } \\
\hline No child & 169 & 49.0 & 32 & 9.3 & 14 & 4.1 & & \\
\hline One or more child(ren) & 49 & 14.2 & 56 & 16.2 & 25 & 7.2 & 58.3 & $0.000 * * *$ \\
\hline \multicolumn{9}{|l|}{ Race/ethnicity } \\
\hline Hausa & 39 & 11.3 & 19 & 5.5 & 9 & 2.6 & & \\
\hline Ibo & 43 & 12.5 & 5 & 1.4 & 5 & 1.4 & & \\
\hline Yoruba & 74 & 21.4 & 27 & 7.8 & 11 & 3.2 & & \\
\hline Other & 62 & 18.0 & 37 & 10.7 & 14 & 4.1 & 13.1 & $0.04 I^{*}$ \\
\hline \multicolumn{9}{|l|}{ Religion } \\
\hline Christian & 172 & 50.3 & 65 & 19.0 & 31 & 9.1 & & \\
\hline Muslim & 45 & 13.2 & 21 & 6.1 & 8 & 2.3 & 0.53 & 0.769 \\
\hline \multicolumn{9}{|l|}{ Employment status } \\
\hline Trainee & 6 & 1.7 & 2 & 0.6 & 7 & 2.0 & & \\
\hline Active service & 210 & 61.2 & 86 & 25.1 & 32 & 9.3 & 19.4 & $0.000 * * *$ \\
\hline \multicolumn{9}{|l|}{ Annual income } \\
\hline Low & 150 & 43.6 & 64 & 18.6 & 28 & 8.1 & & \\
\hline High & 68 & 19.8 & 24 & 7.0 & 10 & 2.9 & 0.69 & 0.708 \\
\hline \multicolumn{9}{|l|}{ Number of partners } \\
\hline Single partner & 107 & 31.0 & 71 & 20.6 & 26 & 7.5 & & \\
\hline Multiple partners & 111 & 32.2 & 17 & 4.9 & 13 & 3.8 & 26.0 & $0.000 * * *$ \\
\hline \multicolumn{9}{|l|}{ Type of relationship } \\
\hline Casual & 124 & 36.4 & 20 & 5.9 & 7 & 2.1 & & \\
\hline Noncasual & 92 & 27.0 & 66 & 19.4 & 32 & 9.4 & 41.45 & $0.000 * * *$ \\
\hline \multicolumn{9}{|c|}{ Personally known someone with HIV } \\
\hline Yes & 57 & 16.5 & 26 & 7.5 & 6 & 1.7 & & \\
\hline No & 161 & 46.7 & 62 & 18.0 & 33 & 9.6 & 0.287 & 0.238 \\
\hline
\end{tabular}

Note: 'Except for race/ethnicity with $\mathrm{df}=6$, all other variables have $\mathrm{df}=2$. 'Marital status: 'single' represents unmarried persons, divorcees, those who were previously married and now separated and the widowed; and 'Married' include those who were legally married or living together as married couples. Significance level: $* P<0.05$; $* * P<0.01 ; * * * P<0.001$.

(Table 2). However, participants that used condoms always $(55.19 \pm 5.64)$ and sometimes $(55.69 \pm 4.51)$ tend to have significantly $(P<0.001)$ positive $\mathrm{CAB}$ than those that never used condoms $(60.15 \pm 6.37)$ during sexual intercourse in the past three months prior to the study. The level of involvement of the participants that used condoms sometimes in HRB and the peers support to condom use they received were significantly lower $(P \leq 0.05)$ than those that used condoms always and those that never used condoms, respectively (Table 2). There were no significant differences $(P>0.05)$ in CUS by the frequency of condom use by participants. 
Table 2 Relationships between HIVIAIDS knowledge, psychosocial and risk behavior variables and frequency of condom use

\begin{tabular}{|c|c|c|c|c|c|}
\hline \multirow[t]{3}{*}{$\overline{\text { Variable }^{a}}$} & \multicolumn{3}{|c|}{ Frequency of condom use } & \multirow[t]{3}{*}{$F$-value } & \multirow[t]{3}{*}{$P$-value } \\
\hline & Always $(n=2 \mid 8)$ & Sometimes $(n=88)$ & Never $(n=39)$ & & \\
\hline & Mean (SD) & Mean (SD) & Mean (SD) & & \\
\hline HAK & $7.47(2.02)$ & $7.61(2.08)$ & $7.59(2.05)$ & 0.17 & $0.842^{\text {ns }}$ \\
\hline$C A B$ & $55.19(5.64)^{\mathrm{a}}$ & $55.69(4.5 \mathrm{I})^{\mathrm{a}}$ & $60.15(6.37)^{\mathrm{b}}$ & 13.75 & $0.000^{* * *}$ \\
\hline HRB & $1 \mathrm{I} .73(1.43)^{\mathrm{a}}$ & $11.16(0.99)^{\mathrm{b}}$ & II.87 (I.24) $)^{\mathrm{a}}$ & 6.86 & $0.00 I^{* * *}$ \\
\hline CUS & $3.14(1.79)$ & $2.99(1.52)$ & $3.07(\mathrm{I} .5 \mathrm{I})$ & 0.20 & $0.818^{\text {ns }}$ \\
\hline SSC & $34.69(3.26)^{\mathrm{a}}$ & $33.50(2.75)^{b}$ & $34.54(4.39)^{\mathrm{a}}$ & 4.18 & $0.016^{*}$ \\
\hline
\end{tabular}

Notes: ${ }^{2}$ Variable scores range: HAK (I-I0); CAB (I7-74); HRB (I0-22); CUS (I-23); SSC (I2-48). Within rows, means (SD) with the different superscripts are significantly different at $P<0.05$. Significance level: $* P<0.05$; ***P $<0.00 \mathrm{I}$; ns, not significant $(P>0.05)$.

Abbreviations: HAK, HIVIAIDS-related knowledge; CAB, condom attitudes and barriers; HRB, HIV risk behaviors; CUS, condom use self-efficacy; SSC, social support to condom use.

\section{Predictors of condom use}

Table 3 presents the result from the univariate analysis of factors associated with consistent and nonconsistent condom use during the past three months prior to the study. Among the independent variables considered in the study, age, marital status, number of children, employment status, type of relationship, $\mathrm{CAB}, \mathrm{HRB}$, and $\mathrm{SSC}$ were significantly associated $(P \leq 0.05)$ with condom use behavior among the participants. Although, majority of the UPORs were generally protective for nonconsistent condom use, participants who were 30 years and above, were $34 \%$ more likely than those below 30 years to use condoms consistently $(\mathrm{UPOR}=1.34$; 95\% CI: 1.16-1.56). Married respondents were more likely to use condoms consistently than were singles (UPOR $=2.85$; 95\% CI: 2.09-3.89) during sexual encounters, while those with one or more children were twice more likely than those with no children to use condoms consistently.

Participants who engage in casual relationships during the past three months were significantly $(P<0.001)$ more likely than those who had noncausal relationships to use condoms consistently (UPOR $=1.70 ; 95 \%$ CI: 1.44-2.00). Participants who exhibited positive $\mathrm{CAB}$ were associated with consistent condom use (UPOR $=1.22 ; 95 \%$ CI: 1.04-1.43) compared to those who had negative attitudes and barriers. However, participants involved in high HRB and those with SSC were $47 \%$ (UPOR $=1.47 ; 95 \%$ CI: $1.08-1.99)$ and $42 \%$ (UPOR $=1.42 ; 95 \%$ CI: $1.08-1.86)$ more likely than those with low HRB or limited SSC, respectively, to use condoms inconsistently (Table 3).

Of the ten predictor variables that met the criteria for entry into the multivariate logistic regression model, only marital status $(P<0.001)$, type of relationship $(P<0.05)$ and $\mathrm{CAB}(P<0.001)$ were the significant predictors $\left(r^{2}=0.37\right)$ of condom use among the participants, after adjusting for all variables in the model (Table 4). Respondents who were married recorded an elevated likelihood of consistent condom use during sexual intercourse (APOR $=7.9 ; 95 \%$ CI: 2.71-13.17), compared to those who were single. However, slightly wide CI associated with the APOR, may indicate a reduced precision of the estimate and calls for caution in interpreting the value. Although $78.4 \%$ of the nonconsistent users of condoms had steady (noncasual) relationships, those that maintained casual relationships were twice more likely than the later to use condoms inconsistently $(\mathrm{APOR}=2.14$; 95\% CI: 1.16-3.94). CAB significantly $(P<0.001)$ predicted condom use among the participants with those having positive $\mathrm{CAB}$ being approximately three times $(\mathrm{APOR}=2.76 ; 95 \%$ CI: $1.52-5.02)$ more likely than those with negative $C A B$ to use condoms consistently (Table 4).

\section{Discussion}

In the present study, we found robust relationships between attitudes toward condom use and condom use behaviors for the overall sample, beyond the effects of sociodemographic and risk characteristics. Overall, majority of the study participants $(63 \%)$ used condoms consistently compared to nonconsistent users (37\%). The social environments in the Nigerian military barracks have significant mixing between groups having high and low sexual risk behavior patterns ${ }^{11}$ and may be responsible for the high level of consistent condom users in our sample. Overall, the preponderance of available epidemiologic studies have reported that when used consistently and correctly, condoms are highly effective in reducing both the rate of HIV transmission and other STDs by $80 \%$ to $90 \%{ }^{13,14}$ and pregnancy by $91 \%$ to $99 \% .^{15}$

A higher proportion of participants in our study reported that they used condoms consistently because their partners welcomed it, compared to the nonconsistent users who felt that condom use with long-term partners was unnecessary (data not shown). About $78 \%$ of the nonconsistent condom 
Table 3 Univariate analysis of factors associated with condom use

\begin{tabular}{|c|c|c|c|c|c|}
\hline \multirow[t]{3}{*}{ Variables } & \multicolumn{4}{|c|}{ Frequency of condom use } & \multirow[t]{3}{*}{$P$-value } \\
\hline & \multicolumn{2}{|c|}{ Consistent $(n=218)$} & \multicolumn{2}{|c|}{ Nonconsistent $(n=127)$} & \\
\hline & $\%$ & UPOR (95\% Cl) & $\%$ & UPOR (95\% CI) & \\
\hline \multicolumn{6}{|l|}{ Age (years) } \\
\hline$<30$ years & 31.2 & 1.00 (referent) & 15.0 & 1.00 (referent) & \\
\hline$\geq 30$ years & 68.8 & $1.34(1.16-1.57)$ & 85.0 & $0.52(0.34-0.80)$ & $0.000^{* * * *}$ \\
\hline \multicolumn{6}{|l|}{ Education level } \\
\hline Less than high school & 11.0 & 1.00 (referent) & 16.7 & 1.00 (referent) & \\
\hline High school and above & 89.0 & $0.82(0.62-1.09)$ & 83.3 & $1.33(0.94-1.88)$ & 0.134 \\
\hline \multicolumn{6}{|l|}{ Marital status } \\
\hline Single & 86.2 & 1.00 (referent) & 37.9 & 1.00 (referent) & \\
\hline Married & 13.8 & $2.85(2.09-3.89)$ & 62.1 & $0.28(0.21-0.37)^{* * * *}$ & $0.000^{* * *}$ \\
\hline \multicolumn{6}{|l|}{ Number of children } \\
\hline No child & 77.5 & 1.00 (referent) & 36.2 & 1.00 (referent) & \\
\hline One or more child(ren) & 22.5 & $2.09(1.65-2.63)$ & 63.8 & $0.34(0.26-0.46)$ & $0.000^{* * * *}$ \\
\hline \multicolumn{6}{|l|}{ Race/ethnicity } \\
\hline Yoruba & 33.9 & 1.00 (referent) & 29.9 & 1.00 (referent) & \\
\hline Other & 66.1 & $1.07(0.91-1.26)$ & 70.1 & $0.89(0.65-1.21)$ & $0.44 I$ \\
\hline \multicolumn{6}{|l|}{ Religion } \\
\hline Christian & 79.3 & 1.00 (referent) & 76.8 & $\mathrm{I} .00$ (referent) & \\
\hline Muslim & 20.7 & $1.06(0.86-1.29)$ & 23.2 & $0.91(0.66-1.27)$ & 0.594 \\
\hline \multicolumn{6}{|l|}{ Employment status } \\
\hline Trainee & 2.8 & 1.00 (referent) & 7.1 & $\mathrm{I} .00$ (referent) & \\
\hline Active service & 97.2 & $1.60(0.86-2.99)$ & 92.9 & $0.60(0.39-0.93)$ & $0.000^{* * * *}$ \\
\hline \multicolumn{6}{|l|}{ Annual income } \\
\hline Low & 68.8 & 1.00 (referent) & 73.0 & 1.00 (referent) & \\
\hline High & 31.2 & $0.93(0.79-1.10)$ & 27.0 & $1.14(0.83-1.57)$ & 0.410 \\
\hline \multicolumn{6}{|l|}{ Number of partners } \\
\hline Single partner & 49.1 & 1.00 (referent) & 76.4 & 1.00 (referent) & \\
\hline Multiple partners & 50.9 & $0.66(0.57-0.78)$ & 23.6 & $2.24(1.58-3.17)$ & 0.060 \\
\hline \multicolumn{6}{|l|}{ Type of relationship } \\
\hline Noncasual & 42.6 & 1.00 (referent) & 78.4 & $\mathrm{I} .00$ (referent) & \\
\hline Casual & 57.4 & $1.70(1.44-2.00)$ & 21.6 & $0.35(0.24-0.50)$ & $0.000^{* * * *}$ \\
\hline \multicolumn{6}{|c|}{ Personally known someone with HIV } \\
\hline No & 73.9 & 1.00 (referent) & 74.8 & 1.00 (referent) & \\
\hline Yes & 26.1 & $1.02(0.85-1.22)$ & 25.2 & $0.97(0.70-1.33)$ & 0.846 \\
\hline \multicolumn{6}{|c|}{ HIVIAIDS-related knowledge } \\
\hline Low & 17.9 & 1.00 (referent) & 17.3 & 1.00 (referent) & \\
\hline High & 82.1 & $1.01(0.82-1.25)$ & 82.7 & $0.98(0.68-1.4 I)$ & 0.894 \\
\hline \multicolumn{6}{|c|}{ Condom attitudes and barriers } \\
\hline Negative & 51.4 & 1.00 (referent) & 37.8 & 1.00 (referent) & \\
\hline Positive & 48.6 & $1.22(1.04-1.43)$ & 62.2 & $0.70(0.53-0.94)$ & $0.015^{*}$ \\
\hline \multicolumn{6}{|l|}{ HIV risk behaviors } \\
\hline Low & 53.7 & 1.00 (referent) & 67.7 & 1.00 (referent) & \\
\hline High & 46.3 & $0.81(0.69-0.95)$ & 32.3 & $1.47(1.08-1.99)$ & $0.011 * *$ \\
\hline \multicolumn{6}{|c|}{ Condom use self-efficacy } \\
\hline Low & 52.8 & 1.00 (referent) & 59.1 & $\mathrm{I} .00$ (referent) & \\
\hline High & 47.2 & $0.91(0.78-1.07)$ & 40.9 & $1.18(0.89-1.56)$ & 0.256 \\
\hline \multicolumn{6}{|c|}{ Social support to condom use } \\
\hline Low & 31.7 & 1.00 (referent) & 44.9 & 1.00 (referent) & \\
\hline High & 68.3 & $0.8 \mathrm{I}(0.67-0.97)$ & 55.1 & I.42 (I.08-I.86) & $0.014^{* *}$ \\
\hline
\end{tabular}

Notes: Significance levels: $* P<0.05 ; * * * P<0.001$.

Abbreviations: referent, reference category; UPOR, unadjusted prevalence odds ratio; $95 \% \mathrm{Cl}, 95 \%$ confidence interval. 
Table 4 Multivariable logistic regression model assessing characteristics associated with condom use

\begin{tabular}{|c|c|c|c|c|}
\hline \multirow[t]{3}{*}{ Factors } & \multicolumn{4}{|c|}{ Frequency of condom use } \\
\hline & \multicolumn{2}{|c|}{ Consistent $(n=218)$} & \multicolumn{2}{|c|}{ Nonconsistent $(n=127)$} \\
\hline & $\%$ & APOR (95\% CI) & $\%$ & APOR $(95 \% \mathrm{Cl})$ \\
\hline \multicolumn{5}{|l|}{ Age (years) } \\
\hline$<30$ years & 31.2 & $\mathrm{I} .00$ (referent) & 15.0 & 1.00 (referent) \\
\hline$\geq 30$ years & 68.8 & $1.30(0.66-2.58)$ & 85.0 & $0.78(0.39-1.52)$ \\
\hline \multicolumn{5}{|l|}{ Education level } \\
\hline Less than high school & 11.0 & $\mathrm{I} .00$ (referent) & 16.7 & 1.00 (referent) \\
\hline High school and above & 89.0 & $0.55(0.26-1.19)$ & 83.3 & $1.81(0.84-3.91)$ \\
\hline \multicolumn{5}{|l|}{ Marital status } \\
\hline Single & 86.2 & $\mathrm{I} .00$ (referent) & 37.9 & 1.00 (referent) \\
\hline Married & 13.8 & $7.93(2.71-13.17)^{* * *}$ & 62.1 & $0.13(0.04-0.37)^{* * *}$ \\
\hline \multicolumn{5}{|l|}{ Number of children } \\
\hline No child & 77.5 & $\mathrm{I} .00$ (referent) & 36.2 & 1.00 (referent) \\
\hline One or more child(ren) & 22.5 & $1.04(0.36-2.99)$ & 63.8 & $0.96(0.33-2.77)$ \\
\hline \multicolumn{5}{|l|}{ Employment status } \\
\hline Trainee & 2.8 & $\mathrm{I} .00$ (referent) & 7.1 & 1.00 (referent) \\
\hline Active service & 97.2 & $1.14(0.29-4.40)$ & 92.9 & $0.88(0.23-3.42)$ \\
\hline \multicolumn{5}{|l|}{ Number of partners } \\
\hline Single partner & 49.1 & $\mathrm{I} .00$ (referent) & 76.4 & 1.00 (referent) \\
\hline Multiple partners & 50.9 & $1.02(0.53-1.96)$ & 23.6 & $0.98(0.51-1.89)$ \\
\hline \multicolumn{5}{|l|}{ Type of relationship } \\
\hline Noncasual & 42.6 & $\mathrm{I} .00$ (referent) & 78.4 & 1.00 (referent) \\
\hline Casual & 57.4 & $0.47(0.25-0.86)^{*}$ & 21.6 & $2.14(1.16-3.94)^{*}$ \\
\hline \multicolumn{5}{|c|}{ Condom attitudes and barriers } \\
\hline Negative & 51.4 & 1.00 (referent) & 37.8 & 1.00 (referent) \\
\hline Positive & 48.6 & $2.76(1.52-5.02)^{* * *}$ & 62.2 & $0.36(0.20-0.66)^{* * *}$ \\
\hline \multicolumn{5}{|l|}{ HIV risk behaviors } \\
\hline Low & 53.7 & 1.00 (referent) & 67.7 & 1.00 (referent) \\
\hline High & 46.3 & $0.82(0.46-1.46)$ & 32.3 & $1.22(0.69-2.16)$ \\
\hline \multicolumn{5}{|c|}{ Social support to condom use } \\
\hline Low & 31.7 & 1.00 (referent) & 44.9 & 1.00 (referent) \\
\hline High & 68.3 & $0.87(0.50-1.54)$ & 55.1 & $1.15(0.65-2.02)$ \\
\hline
\end{tabular}

Notes: Only factors that met the entry criteria of $P \leqslant 0.10$ in the univariate analysis were included in the multivariate logistic regression model; Final Model Likelihood ratio test: $\chi^{2}=104.4(\mathrm{df}=10)^{* * *}$; Pseudo R-Square (Nagelkerke) $=0.37$. Significance level: $* P<0.05 ; * * * P<0.001$.

Abbreviations: referent, reference category; APOR = adjusted Prevalence odds ratio; $95 \% \mathrm{Cl}=95 \%$ confidence interval.

users in our study had steady partners and were unwilling to use condoms because they believed condom use connotes distrust, lack of intimacy, and they did not feel that their partners were at risk. This is in line with most military personnel belief, who by virtue of their training and accepted norms, are imbued with feelings of invulnerability that distort their perceptions of risk. This suggests that educational programs aimed at enabling individuals to correctly assess their own HIV risk, encouraging behavior change based on self-assessment of risk, and development of negotiation skills with partners, could increase condom use among those practicing unprotected sex. A number of studies have shown that improved partner communication skills are important in increasing condom use. ${ }^{23-26}$

We found in our study that older respondents ( 30 years and above) were $34 \%$ more likely than younger ones to use a condom consistently, a finding that was similarly noted by some researchers. ${ }^{27,28}$ This observation may help explain in part why young women accounted for the persistently high number $(61.5 \%)$ of adults aged 15 years and above living with HIV disease in Nigeria. ${ }^{2}$ Other studies have found the reverse to be true: that younger subjects were significantly more likely to report frequent and consistent condom use during intercourse. ${ }^{23,29}$ Also, we found that 
married female military personnel were three times more likely than singles to use condoms consistently; likewise those with one or more children, were twice more likely to do so. Apart from attempting to protect against unwanted pregnancy, they could also be using condoms to protect themselves from HIV or STDs because of their partner's infidelity and the associated risky behaviors and lifestyles common in the Nigerian military barracks. We noted that $56.4 \%$ of our study population had not been tested for $\mathrm{HIV}$, and of this proportion, $28.9 \%$ of them were classified as being at high risk of contracting HIV because of their lifestyles, which include drug and alcohol abuse and engaging in unprotected sexual relationships with casuals. The bivariate analysis showed a high prevalence of consistent condom use on casual partners. In contrast, the nonconsistent users were $65 \%$ less likely to use condoms on casual partners, suggesting that this group would be at elevated risk of HIV/STDs infection. Similarly, 36\% of Nigerian uniformed service personnel reported that they had not thought of using condoms with their casual partners. ${ }^{12}$ These observations suggest that HIV risk assessment should be based both on personal perception of risk and the epidemiologic notions of risk. Although behavior changes may be indicative of one's perception of risk, but recognizing one's current behaviors as risky is the first step toward behavior changes such as adopting condom use. ${ }^{30}$ With the high HIV prevalence in Nigeria, ${ }^{1}$ it is important to encourage condom use in all types of sexual relationships, including consensual and legal unions, since both married and unmarried individuals tend to engage in risky sexual behaviors eg, multiple partners and unprotected sex with nonregular partners).

Active service personnel in the sample population were 1.6 times more likely than trainees to use condoms consistently. Cost has been reported as a barrier to condom use. ${ }^{31}$ For optimal condom use, all barriers to condom acquisition should be removed. Free condoms should be made available to military personnel to encourage their use by persons at risk of HIV and other sexually transmitted diseases.

CUS is an important factor in the promotion of safer sex. But we noted that this variable was not significantly associated with condom use at all levels in our study, contrary to the findings of other researchers that higher levels of self-efficacy were associated with condom use. ${ }^{27,32}$ Self-efficacy is assessed frequently in HIV prevention research but there has been mixed evidence for the relationship between self-efficacy, safer sex, and sexual risk behavior. ${ }^{33}$ It is however, possible that some methodological issues may have attenuated observed efficacy-behavior relationships in our study population. Weinhardt et al similarly, reported that self-efficacy risk reduction associations may be influenced by ceiling effects, response bias, and measurement error associated with self-report measures of risk behavior. ${ }^{34}$ In an earlier study using the same population ${ }^{22}$ we reported that more than $70 \%$ of our population had lower CUS and were engaged in risk-taking behaviors, despite having a high degree of HIV/AIDS knowledge.

Bivariate analysis indicated that participants who perceived high social support from peers were $42 \%$ more likely than those receiving low peers support to use condoms inconsistently. Although this factor was not significant after adjusting for other variables in the final model, it may serve as a pointer for unraveling misconceptions about condoms, and as an entry for HIV prevention efforts in this group. Since the norms within a given social network can help or retard the efforts of an individual to change behaviors, especially those related to sexual practices, such efforts should tap into existing social dynamics and patterns of communication to promote pro-condom norms. Social support is important in facilitating an individual's change either in attitude or behaviors; and such changes take place within a network of social influences. ${ }^{35}$ According to Bandura, social networks are important sources of social support, and social support is vital to self-efficacy. ${ }^{36}$ Social network research also indicates that close bonds with network members may be a protective factor independent of self-efficacy. ${ }^{36,37}$ This statement supports our current findings.

Consistent and sustained condom use during sex is considered very important in the fight against HIV/AIDS and understanding the predictors of condom use can enhance effective interventions to elevate usage. In our study, we noted that marital status, type of relationship (noncasual and casual) and $\mathrm{CAB}$ were significant predictors of condom use during sex, and explained as much as $37 \%$ of the variability in condom use in the sample population. Married women had a high prevalence $(\mathrm{APOR}=7.9)$ of consistent condom use than singles. This observation is not consistent with previous findings in the general population ${ }^{4}$ and national youth service corp members ${ }^{38}$ in Nigeria, where condom use was more common among women who were single than among married women. However, it was not possible to distinguish condom use for family planning purposes from condom use to prevent STDs, in particular HIV infection. These, in addition to the small proportion of married women involved (13.8\%), may offer plausible explanation for 
the high APOR recorded. Since condom use remains an important approach for prevention of HIV and unwanted pregnancies among married couples and others in longterm partnerships, promotion of condoms as contraceptive methods or as dual protection against unwanted pregnancies and STDs may be an appropriate strategy among married women in this population.

Relationship dynamics also play a significant role in determining condom use. Participants with casual partners were twice more likely to use condoms inconsistently than those involved in steady relationships. This finding collaborates with those of Chatterjee et al who also noted lower rates of condom use with casual partners in the inner city African-American communities. ${ }^{39}$ Unprotected sex with a casual partner has been documented as a risk factor for HIV infection among mobile populations like the military. ${ }^{16,22}$ Reasons such as financial dependence on male partners, feeling invincible, low self-esteem coupled with the need to feel loved by a male figure, and alcohol and drug use have been given for such risky behaviors. , $^{4,16,40}$

There was a significant mix of outcomes on condom use and barriers, with participants having positive attitudes being three times more likely than those with negative attitudes to condom use consistently during sexual intercourse. Though some of the nonconsistent users had negative attitudes, they used condoms in perceived high-risk situations but reported that they dislike condoms because its use reduces sexual pleasure, a reason that has commonly been cited by other researchers for nonuse of condoms. ${ }^{12,22,27}$ Thus, a key to encouraging safer sex practices in this group is to find effective strategies for personalizing the risk that they take when they practice unsafe sex. Once risk perceptions are heightened, a focus on positive attitudes about condom use is likely to be most effective. In our study, the level of HIV knowledge, and perceived risk of getting HIV through sexual intercourse and peer social support were not significantly associated with consistent condom use in the multivariate analysis. These findings are consistent with results from other studies. ${ }^{6-9,23}$

\section{Limitations}

When interpreting the results presented here, it may be necessary to take into account factors that might have influenced our findings. Because a cross-sectional design was used, we were unable to examine the direction of causality between condom attitudes and condom behaviors. It is also appropriate to indicate the limitations of self-reports, especially for sensitive topics related to sexual practices and behaviors. Information bias may affect our results, since some participants could have given socially acceptable answers in response to sensitive questions. Given that the study used military cantonments from one of the six geopolitical regions in Nigeria, the findings may not be generalizable or representative of the female military personnel in Nigeria. Each of the regions has different socio-cultural characteristics and environmental settings that influence the type of sexual risk behaviors personnel serving in such areas are engaged in.

Furthermore, the CAB observed in the present study may be unique to our sample and should not be generalized to other members of populations who engage in risky behaviors. Because condom use behavior was measured retrospectively, and attitudes were measured at the time of the survey, we do not know whether attitudes preceded behavior, or attitudes were formed on the basis of the reported behaviors. It was not determined whether failure to use condoms resulted from use of other contraceptive methods or other contraceptive methods were used because of the women's reluctance to have their partners use condoms.

Finally, our instrument and/or analysis may have inadvertently omitted some predictors of consistent and nonconsistent condom use. Thus, in-depth studies using longitudinal designs would be necessary to understand the nature of the relations between these constructs, and to assess the significance, and stability of current predictors of condom use in the sample population. Attention should be given to community-level and structural-level factors affecting HIV infection and transmission in this population.

\section{Conclusion}

In summary, despite these limitations, our study found a comparatively high level of condom use among female military personnel in Nigeria that was significantly predicted by marital status, type of relationship (noncausal and casual) and condom use attitudes and barriers. In addition, the significant HRB exhibited by participants, coupled with strong peer social support recorded in the univariate analysis, call for gender-specific intervention programs taking into consideration the predictor variables. Such programs would help to increase awareness about the positive aspects of condom use, and work to eliminate misconceptions about condoms, partner risk level, HIV, and distribute free male and female condoms. These are likely to be successful in decreasing sexual risk behaviors in this population. It is also important that such intervention program should emphasize 
the effectiveness of condoms in preventing the spread of HIV and other STDs and in protecting against unwanted pregnancy, while taking into account the psychosocial factors, social environments and lifestyles prevalent in the Nigerian military barracks.

\section{Acknowledgments}

This research was supported by a grant from the United States National Institute of Mental Health (Grant number RO1 MH073361-02). The authors report no conflicts of interest with respect to authorship and/or publication of this article.

\section{References}

1. UNIAIDS.ORG.[ONLINE].UNAIDS 2008 Report on the global AIDS epidemic. Available from http://www.unaids.org/en/KnowledgeCentre/ HIVData/GlobalReport/2008/. Accessed July 30, 2009.

2. UNAIDS Nigeria country profile. Nigeria UNGASS Report 2007. 2008 Jan 31. p. 29

3. USAID/Nigeria: Investing in People-HIV/AIDS/TB. Comprehensive Integrated Approach to HIV/AIDS Prevention and Care in Nigeria (CIHPAC). 2009 March 05.

4. Sunmola AM, Olley BO, Oso GE. Predictors of condom use among sexually active persons involved in compulsory national service in Ibadan, Nigeria. Health Educ Res. 2007;22(4):459-472.

5. Imade G, Sagay A, Egah D, et al. Prevalence of HIV and other sexually transmissible infections in relation to lemon lime douching among female sex workers in Jos, Nigeria. Sex Health. 2008;5(1):55-60.

6. Akintola O. Knowledge about AIDS and risky sexual behavior of commercial drivers in Ibadan. MPH Dissertation. University of Ibadan, Nigeria. 2000.

7. Nwokoji UA, Ajuwon AJ. Knowledge of AIDS and HIV risk-related sexual behavior among Nigerian naval personnel. BMC Public Health. 2004;4:24

8. Essien EJ, Ogungbade OO, Kamiru HN, Ekong E, Ward D, Holmes L. Emerging socio-demographic and lifestyle predictors of intention to use a condom in human immunodeficiency virus (HIV) intervention among uniformed services personnel. Mil Med. 2006;171(10):1027-1034.

9. Okulate GT, Jones OB, Olorunda MB. Condom use and other HIV risk issues among Nigeria soldiers: challenges for identifying peer educators. AIDS Care. 2008;20(8):911-916.

10. Calderón MR. Civil-Military Collaboration. The HIV/AIDS prevention and control SYNOPSIS Series. Family Health International. 1997 November. p. 49.

11. Temoshok LR, Kingma SJ. HIV exposure risk in military populations: An uncharted prevention frontier. International Conference on AIDS, 1996 July 7-12. 11(1):48. Abstract No.Mo.D.354

12. Essien J, Meshack A, Ekong E, et al. Effectiveness of a situationallybased HIV risk-reduction intervention for the Nigerian uniformed services on readiness to adopt condom use with casual partners. Counselling, Psychotherapy, and Health. 2005;1(1):19-30.

13. Hearst N, Chen S. Condom promotion for AIDS prevention in the developing world: is it working? Stud Fam Plann. 2004;35(1):39-47.

14. Weller S, Davis K. Condom effectiveness in reducing heterosexual HIV transmission. Cochrane Database Syst Rev. 2002;(1):CD003255.

15. Davis K, Weller S. The effectiveness of condoms in reducing heterosexual transmission of HIV. Fam Plann Perspect. 1999;31(6):272-279.

16. Adebajo SB, Mafeni J, Moreland S, et al. Knowledge, attitudes and sexual behavior among Nigerian military concerning HIV/AIDS and STD: Final Technical Report. Abuja, Nigeria. POLICY Project. 2002.
17. Hatzell T, Feldblum P, Homan R, et al. The female condom: is "just as good" good enough? Sex Transm Dis. 2003;30(5):440-441.

18. Musaba E, Morrison CS, Sunkutu MR, et al. Long-term use of the female condom among couples at high risk of human immunodeficiency virus infection in Zambia. Sex Trans Dis. 1998;25(5): 260-264.

19. USAID. How the female condom affects levels of protected sex. Family Health International (FHI) FHI Research Briefs on the Female Condom. 2009; No. 5.

20. Essien J, Monjok E, Ekong E, et al. Effectiveness of a video-based cognitive-behavioral skills building HIV risk reduction intervention for female military personnel. IAS 2009: Proceeding of the 5th International AIDS Society conference on HIV pathogenesis, treatment and prevention. 2009 July 19-22; Cape Town, South Africa.

21. Kalichman SC, Cherry C, Browne-Sperling F. Effectiveness of a video-based motivational skills-building HIV risk-reduction intervention for inner-city African American men. J Consult Clin Psychol. 1999;67(6):959-966.

22. Essien J, Monjok E, Ekong E, et al. Correlates of HIV knowledge and sexual risk behaviors among female military personnel. AIDS Behav. 2010; In press.

23. Bobrova N, Sergeev O, Grechukhina T, et al. Social-cognitive predictors of consistent condom use among young people in Moscow. Perspect Sex Reprod Health. 2005;37(4):174-178.

24. Greig FE, Koopman C. Multilevel analysis of women's empowerment and HIV prevention: quantitative survey results from a preliminary study in Botswana. AIDS Behav. 2003;7(2):195-208.

25. Kanekar A, Sharma M. Using social cognitive theory to predict safer sex behaviors in African American college students. Acta Didactica Napocensia. 2009; 2:(2). Available from: http://dppd.ubbcluj.ro/adn/ article_2_2_6.pdf. Accessed on March 10, 2010.

26. World Health Organization (WHO). Global guidance briefs on HIV interventions for young people-HIV interventions for most-at-risk young people. Available from: http://www.who.int/child_adolescent_health/ documents/iatt_hivandyoungpeople/en/index.html. Accessed October $29,2009$.

27. Adih WK, Alexander CS. Determinants of condom use to prevent HIV infection among youth in Ghana. J Adolesc Health. 1999;24(1): 63-72.

28. Akarro RR. Some factors associated with condom use among bar maids in Tanzania. J Biosoc Sci. 2009;41(1):125-137.

29. Pendergrast RA, DuRant RH, et al. Attitudinal and behavioral correlates of condom use in urban adolescents adolescent males. J Adolesc Health. 1992;13:33-39.

30. Catania JA, Kegeles SM, Coates TJ. Towards an understanding of risk behavior: an AIDS risk reduction model (ARRM). Health Educ $Q$. 1990;17:53-72.

31. Cohen D, Scribner R, Bedimo R, et al. Cost as a barrier to condom use: the evidence for condom subsidies in the United States. Am J Public Health. 1999;89:567-568.

32. Sayles JN, Pettifor A, Wong MD, et al. Factors associated with self-efficacy for condom use and sexual negotiation among South African youth. J Acquir Immune Defic Syndr. 2006;43(2):226-233.

33. Forsyth AD, Carey MP, Fuqua RW. Evaluation of the validity of Condom Use Self-Efficacy Scale (CUSES) in young men using two behavioral simulations. Health Psychol. 1997; 16(2):175-178.

34. Weinhardt LS, Forsyth AD, Carey MP, et al. Reliability and validity of self-report measures of HIV-related sexual behavior: Progress since 1990 and recommendations for research and practice. Arch Sex Behav. 1998;27:155-180.

35. Williams EE. Women of courage: Commercial sex workers mobilize for HIV/AIDS prevention in Nigeria. AID Scaptions. 1994;1(2):19-22.

36. Bandura A. Social cognitive theory and exercise of control over HIV infection. In: DiClemente RJ, Peterson JL, editors. Preventing AIDS Theories and Methods of Behavioral Interventions. New York, NY: Plenum Press; 1994. p. 25-59. 
37. Montoya ID. Social network ties, self-efficacy, and condom use among women who use crack cocaine: A pilot study. Subst Use Misuse. 1998; 33(10):2049-2073.

38. Messersmith LJ, Kane T, Odebiyi IA, et al. Who's at risk? Men's STD experience and condom use in southwest Nigeria. Stud Fam Plan. 2000;31:203-216.
39. Chatterjee N, Hosain GM, Williams S. Condom use with steady and casual partners in inner city African-American communities. Sex Transm Infect. 2006;82:238-242.

40. CDC. HIV Transmission among Black Women - North Carolina. MMWR. 2005;54:89-94.

\section{Publish your work in this journal}

HIV/AIDS - Research and Palliative Care is an international, peerreviewed open-access journal focusing on advances in research in HIV, its clinical progression and management options including antiviral treatment, palliative care and public healthcare policies to control viral spread. The journal welcomes original research, basic science, clinical \& epidemiological studies, reviews \& evaluations, expert opinion \& commentary, case reports \& extended reports. The manuscript management system is completely online and includes a very quick and fair peer-review system. Visit http://www.dovepress.com/ testimonials.php to read real quotes from published authors. 